\title{
Electromagnetic Action of Heavy-Current Equipment Operating With Power Frequency
}

\author{
Karol Bednarek \\ Institute of Electrical Engineering and Electronics, Poznań University of Technology, \\ Poznań, Poland
}

The paper presents an analysis of the effect of magnetic fields of power frequency generated by heavy-current electric equipment on the environment. The results of computation and measurements of the magnetic field in the vicinity of power busducts are included. Possible hazards are considered that result from the effects of the magnetic field on workers present in the vicinity of busducts as well as secondary hazards caused by the degrading effect of the magnetic field on ferromagnetic structural materials (in reinforced concrete structures). Attention is given to an ergonomic aspect of interaction of the magnetic field with cathode ray tube computer monitors (annoying oscillation of the image).

electromagnetic action heavy-current equipment power frequency calculation and measurements of EMF ergonomic aspect

\section{INTRODUCTION}

Development of technical civilization during recent decades has been accompanied to a significant degree by an increasing application of electric and electronic systems, automatization of manufacturing processes, and transmission and processing of information. This, in turn, is unavoidably related to production and delivery of growing amounts of electric power. Operation of all these devices goes together with generation of electromagnetic fields (EMF) of highly differentiated frequencies in the range from gigahertz (related to radiolocation, mobile telecommunication or microwave technology), through broadcasting waves, to low frequencies (chiefly power network frequencies) and constant fields (in particular circumstances fields of maximal frequencies, in the range of ionizing radiation, can be emitted too). In some circumstances the fields are generated and emitted intentionally, e.g., in telecommunication systems, while in other cases they are an unwanted result of the operation of some systems and equipment.
An important part of those interactions are fields of mains frequency (extremely low frequencies) caused by transmission of electric power. They are emitted by power elements, generating, switching and transmission devices that interact with the environment, often becoming a hazard for people.

Various hazards are caused by electromagnetic fields of low frequencies [1, 2, 3, 4]. They are mainly related to the effect of a current induced by the electromagnetic fields in the body and cellular membranes (particularly the excitable ones). The fields also interact with the elements and devices located in the environment, the consequences of which can threaten human safety or adversely affect the ergonomics of human activity. This is so because correct identification of the interaction is key to correct and safe operation of the equipment and the need of meeting the provisions of regulations and standards on their operation.

This paper presents the computation and measurement results of the magnetic field generated in the proximity of three-phase power busducts. The effect of this field on the human

Correspondence and requests for offprints should be sent to Karol Bednarek, Institute of Electrical Engineering and Electronics, Poznań University of Technology, Piotrowo 3a, 60-965 Poznań, Poland. E-mail: <Karol.Bednarek@put.poznan.pl>. 
body, structures made of ferromagnetic materials and other systems located in the neighbourhood were analysed. Possible hazards to people approaching such locations or working there, and possible worsening of working conditions (i.e., ergonomic factors) were considered.

\section{NORMATIVE CONDITION RELATED TO THE EFFECT OF THE ELECTROMAGNETIC FIELD ON PEOPLE}

The electromagnetic field is represented by factors that can negatively affect people both in their working and living environments. Basic protection of the human being against electromagnetic fields consists in determining admissible levels of the intensity of the field (or possibly other values defining the intensity of the interaction) in which people may stay without a deterioration of their health and general wellbeing.

Directive 2004/40/EC provides legal regulations pertaining to the protection of people against electromagnetic radiation; they are based on data provided by the International Commission on Non-Ionizing Radiation Protection (ICNIRP), considered as recommendations for European Union states [5, 6, 7]. Admissible values of the intensity of the interacting field complying with those documents can be also found elsewhere [2, 8].

These are values of the fields determined with regard to the effects of absorption of the electromagnetic field power in the form of the induction current flowing through the tissues or resulting in temperature increase, burns and paralysis $[3,8,9,10]$. The results of long-term exposure (including possible carcinogenic effects) are not taken into account, since to date there has not been sufficient scientific proofs of these hypotheses.

The recommendations of EU Directives allow individual home standards provided that the protection related thereto is not worse than the one of the Directive. Some European countries implemented recommendations based on ICNIRP guidelines [6]. Other ones introduced their own, more severe standards. In Poland, there is a regulation of the Minister of Labour and Social Policy [11]. It defines limit values of the strength of electric $\mathrm{E}$ and magnetic $\mathrm{H}$ fields for EMF interaction with the human body in the working environment (according to the frequency of the field) as

- prohibited exposure $\left[\mathrm{E}_{2}(\mathrm{f}), \mathrm{H}_{2}(\mathrm{f})\right]$; workers are not allowed to stay where the field level of the intensity exceeds prohibited exposure (in exceptional cases the stay is permitted in screened protective clothes);

- occupational exposure [ $\left.\mathrm{E}_{1}(\mathrm{f}), \mathrm{H}_{1}(\mathrm{f})\right]$; workers can stay for a limited period (under 8 h) where the field level of the intensity exceeds occupational exposure (but is below the prohibited level) provided the dose of admissible exposure is not exceeded. The duration of admissible exposure is determined by measuring the field at the workstand (because of the requirement of observing the dose of admissible exposure; the so-called exposure factor $W$ );

- non-occupational exposure $\left[\mathrm{E}_{0}(\mathrm{f}), \mathrm{H}_{0}(\mathrm{f})\right]$; there is no restriction on staying in a field whose level of intensity is below the limit. If the level of intensity exceeds non-occupational exposure, which is below the occupational exposure threshold, workers can stay throughout their working shift near the sources of that field.

Poland's regulation lists thresholds of exposure limits (for various frequency bands) [11]. This document shows that the admissible strength of the magnetic field interacting with the human body for the frequency of $50 \mathrm{~Hz}$ is, according to Directive 2004/40/EC, $400 \mathrm{~A} / \mathrm{m}$ (which corresponds to magnetic flux density $B=0.5 \mathrm{mT}$ in the air environment) [5], while according to Poland's regulation, the threshold of occupational exposure to magnetic components is $200 \mathrm{~A} / \mathrm{m}$ ( $B=0.25 \mathrm{mT}$ for air) (see also Bednarek [1], Karpowicz, Hietanen and Gryz [2] and Karpowicz and Gryz [8]).

In Poland there are separate standards for the general population (in the living environment). According to the regulation of the Minister of 
Environment, the admissible strength of the magnetic field for the frequency of $50 \mathrm{~Hz}$ is $60 \mathrm{~A} / \mathrm{m}$ (which corresponds to $B=0.075 \mathrm{mT}$ for the air environment) [12].

\section{DESCRIPTION OF THE SYSTEM}

Among the elements of the electric power supply there are heavy-current transmission lines (power busducts). They are used in almost all locations of a power system, in the range of medium voltage, to transmit power of up to 200 MVA. They are used

- to transmit power to mines, steel works, large industrial plants or city centres;

- in large buildings, to connect supply networks to transformers;
- in power plants, to connect generators to unit transformers and transformers to mediumvoltage switchgears;

- as heavy duty power outlets in particularly difficult conditions, e.g., in underground hydroelectric power stations;

- to connect switchgear sections, etc.

This paper considers three-phase heavycurrent busducts in plane arrangement with composite epoxy-resin insulation (Figure 1). Due to the values of the current of up to several kiloamperes, they are sources of a strong magnetic field $[4,13,14]$. The interaction occurs in a near field so the energy can be absorbed by objects located in the field. The field emitted by the sources directly affects workers present in the proximity of the devices and objects located nearby.

(a)

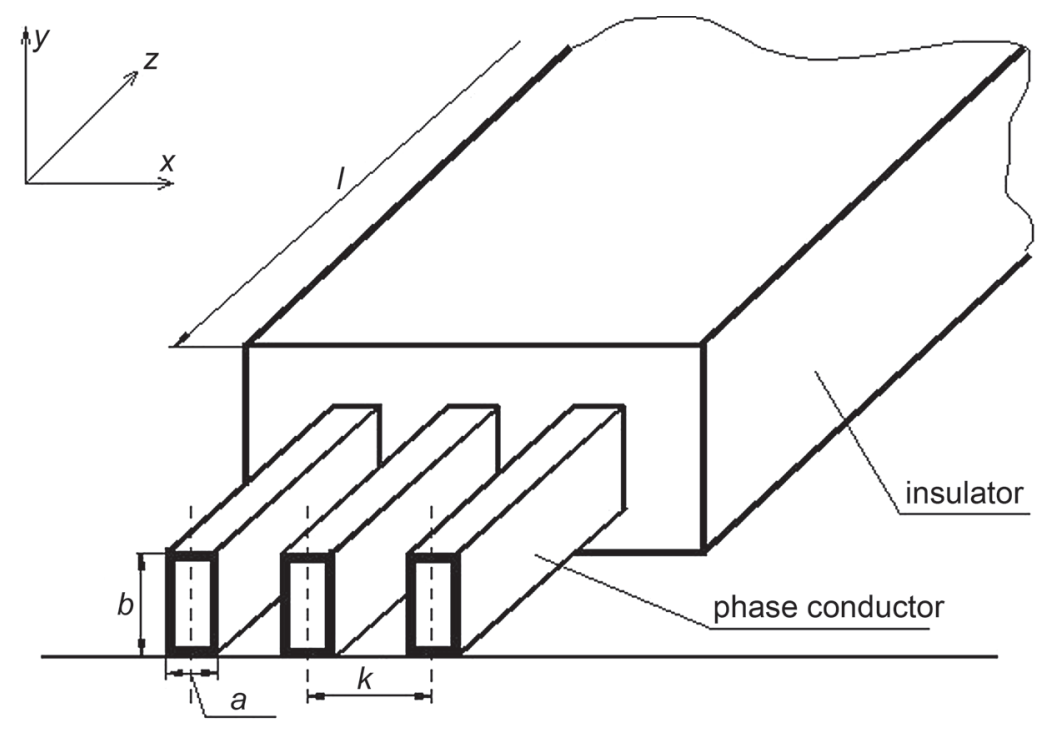

(b)

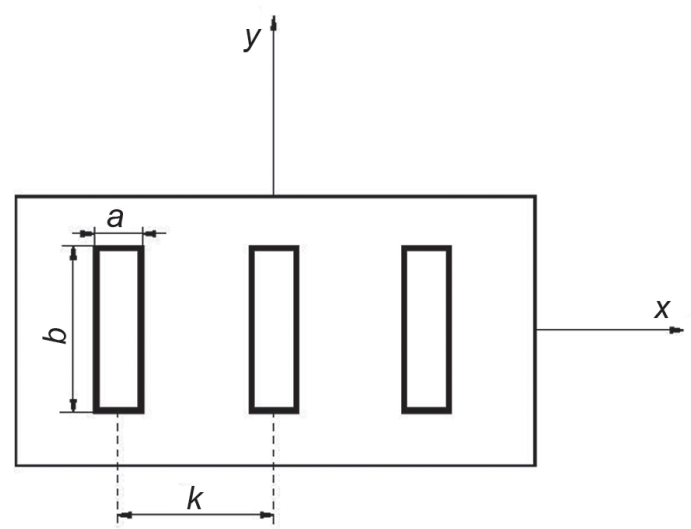

Figure 1. Geometry of two system: (a) configuration of a busduct, (b) a busduct in a two-dimensional system (cross-section). Notes. $a, b$-dimensions of conductors, $k$-distance between axes of conductors. 


\section{CALCULATION OF MAGNETIC FLUX DENSITY AROUND THE BUSDUCTS}

Magnetic flux density at various distances from a three-phase heavy-current busduct can be calculated analytically, which is not very complicated. Nevertheless, because of the more advanced computation that would have to follow (an electrodynamical analysis of a magnetic field generated with ferromagnetic elements near busducts), the distribution of the magnetic flux

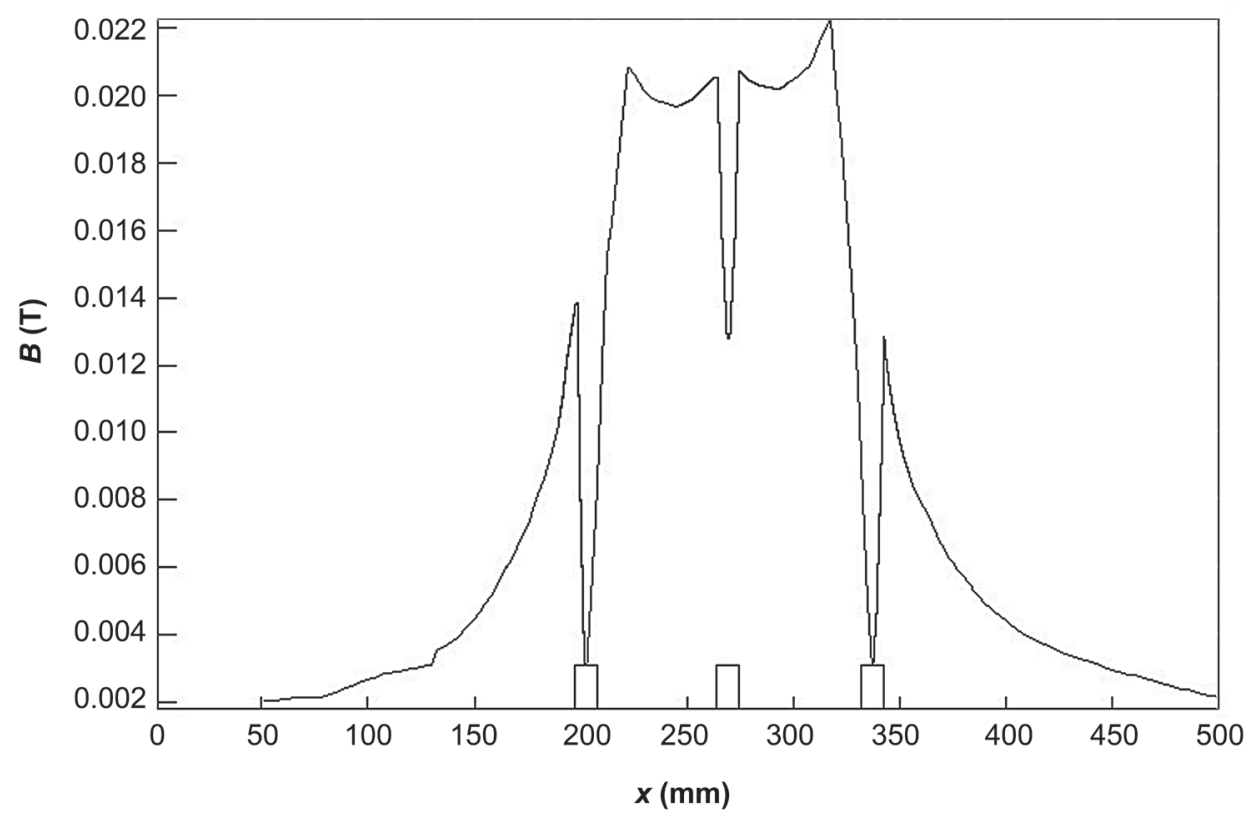

Figure 2. Distribution of magnetic flux density $B(T)$ on the $x$ axis of the phase conductors for the system in Figure $1 \mathrm{~b}$, with phase current of $I_{\mathrm{n}}=1250 \mathrm{~A}$ and the distance between the axes of the conductors $k=62 \mathrm{~mm}$. Notes. $a, b$-dimensions of the conductors.

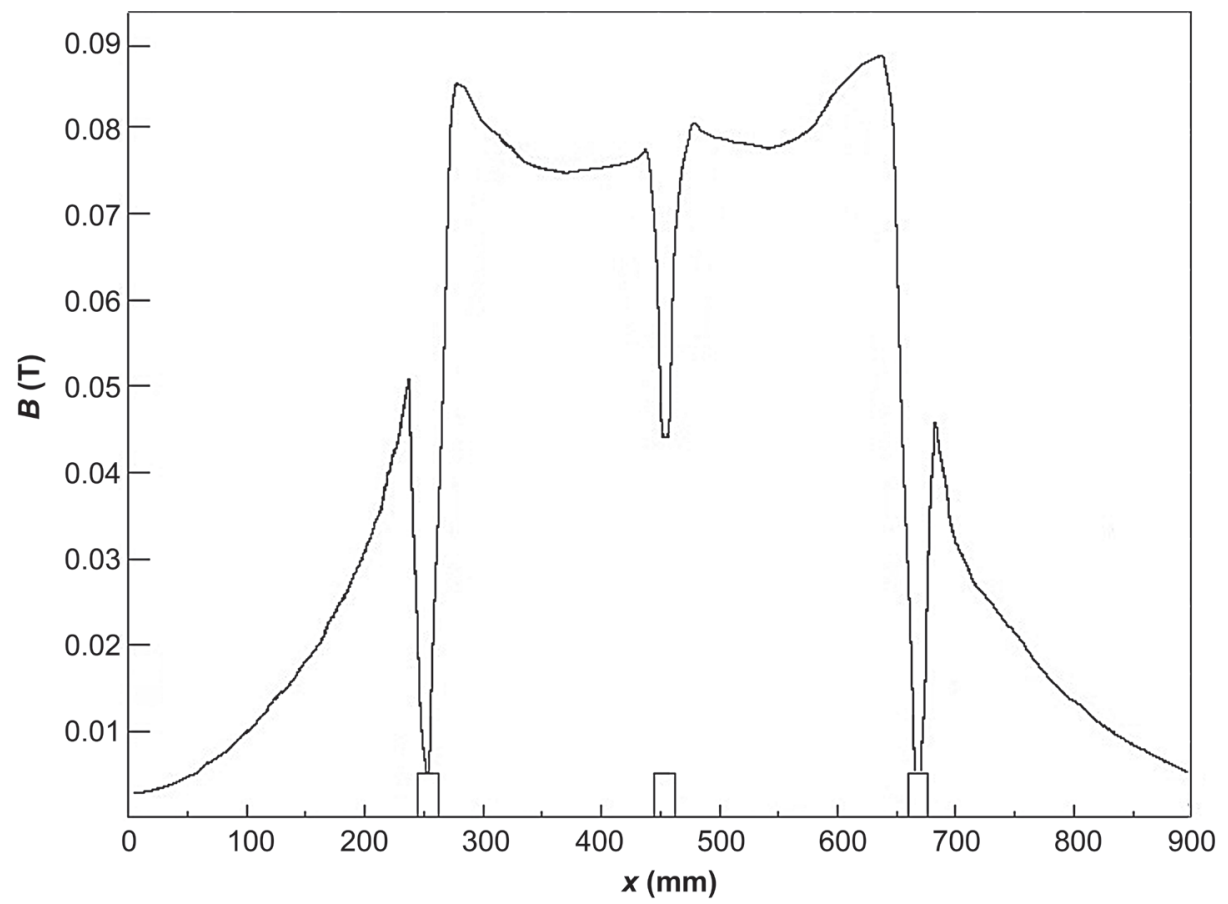

Figure 3. Distribution of magnetic flux density $B(T)$ on the $x$ axis of the phase conductors for the system in Figure $1 \mathrm{~b}$, with phase current of $I_{n}=4000 \mathrm{~A}$ and the distance between the axes of the conductors $k=212 \mathrm{~mm}$. 
density was calculated numerically. This was done with software for analysing electromagnetic fields (Opera 2D from Vector Fields, UK). The finite element method was used to solve electromagnetic problems with Laplace's, Poisson's and diffusion equations [4, 13].

The root-mean-square (rms) value of magnetic flux density in the vicinity of heavy-current busducts (for a system including a ferromagnetic frame above the busduct) was calculated for 1250 A. For this variant the distance between the axes of the conductors was $k=62 \mathrm{~mm}$, i.e., the distance between the walls of neighbouring conductors was $50 \mathrm{~mm}$, and for $4000 \mathrm{~A}$ ( $k=212 \mathrm{~mm}$, the distance between the walls of the conductors was $200 \mathrm{~mm}$ ). The dimensions of the conductors were $a=12 \mathrm{~mm}$ and $b=80 \mathrm{~mm}$. The discrepancy in the arrangement of the conductors ( $k$ variations) resulted from many multivariant computations from which only $k=62 \mathrm{~mm}$ (for $1250 \mathrm{~A}$, which was consistent with the actual parameters of the system) and $k=212 \mathrm{~mm}$ (for $4000 \mathrm{~A}$ assumed to analyse the effect of variation of the interconductor distance, the current level and the magnetic field distribution) were selected as representative. To observe maximal values of magnetic flux density of the interacting field, the field distribution was computed in the nearest vicinity of the phase conductors (along the $x$ axis) in the system in Figure $1 b$. Figures $2-3$ show the results of the computation.

For the current of 1250 A the maximal value of magnetic flux density near the outside surface of the conductor was $14 \mathrm{mT}$, while $0.04 \mathrm{~m}$ from the conductor $B=7 \mathrm{mT}(0.02 \mathrm{~m}$ from the surface of the insulation material of the busduct). For phase current of $4000 \mathrm{~A}$, maximal magnetic flux density near the outside surface of the conductor was $50 \mathrm{mT}$, while $0.04 \mathrm{~m}$ from the conductor $B=30 \mathrm{mT}$ (in this case the increase in $B$ primarily resulted from higher current value and greater distance between the phase conductors).

\section{RESULTS OF MAGNETIC FIELD MEASUREMENT IN A PHYSICAL SYSTEM}

Correctness of the assumed computation model and the reality of the results of the considered physical values so obtained can be checked by measuring those values at physical objects. Therefore, the magnetic flux density was measured at various distances from the busducts (in the system in Figure 1, along the $x$ axis). The busducts were supplied with the current $3 \times 1250$ A from TW25 heavy-current transformers.

Two slow-varying measuring devices were used: a three-axial device for measuring the magnetic field, Tracer 3D (USA), and a device for measuring longitudinal and cross components of the magnetic field, hand-held a gauss/tesla meter, model 40 (Bell, USA). The use of equipment for measuring mutually complementary parameters made the analyses possible.

Figure 4 shows the results of the measurements of magnetic flux density: its longitudinal $B_{1}$ and cross $B_{\mathrm{c}}$ components, and the results of measurements performed in a three-axial mode, giving the rms values of magnetic flux density $B$ at various distances $d$ from the busduct (i.e., from the surface of the insulation material). Figure 5 shows rms values of magnetic flux density $B$ for greater distances from the busducts.

The results of measurements and calculations are in step with each other, which confirms the correctness of the assumed computation model. Computations and measurements of magnetic flux density around the busducts supplied with the current of $1250 \mathrm{~A}$ made it possible to establish that the magnetic flux density several centimeters from the equipment is several milliteslas. Tens of centimeters from the devices magnetic flux density $B=0.1-0.5 \mathrm{mT}$, while $2 \mathrm{~m}$ from the busducts $B=20 \mu \mathrm{T}$. So, during the flow of very large current a very high magnetic field can form rather close to the busduct. Nevertheless, the arrangement in which on one side of a partition there are workstands, whereas on the other there are busducts should be avoided. The situation is similar if busducts are 


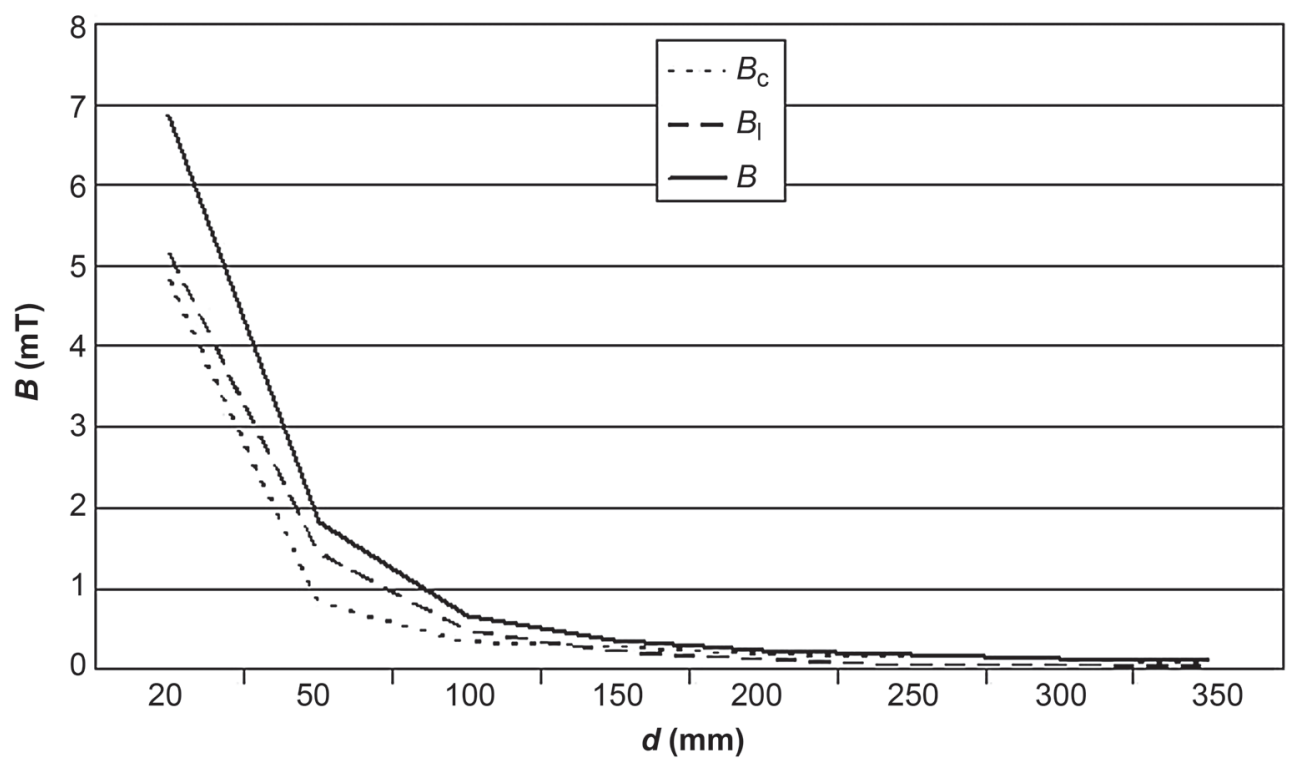

Figure 4. Dependence of magnetic flux density $B(\mathrm{mT})$, longitudinal $B_{1}(\mathrm{mT})$ and cross $B_{\mathrm{c}}(\mathrm{mT})$ components of the magnetic flux density vector as functions of the distance from the busduct $d(\mathrm{~mm})$.

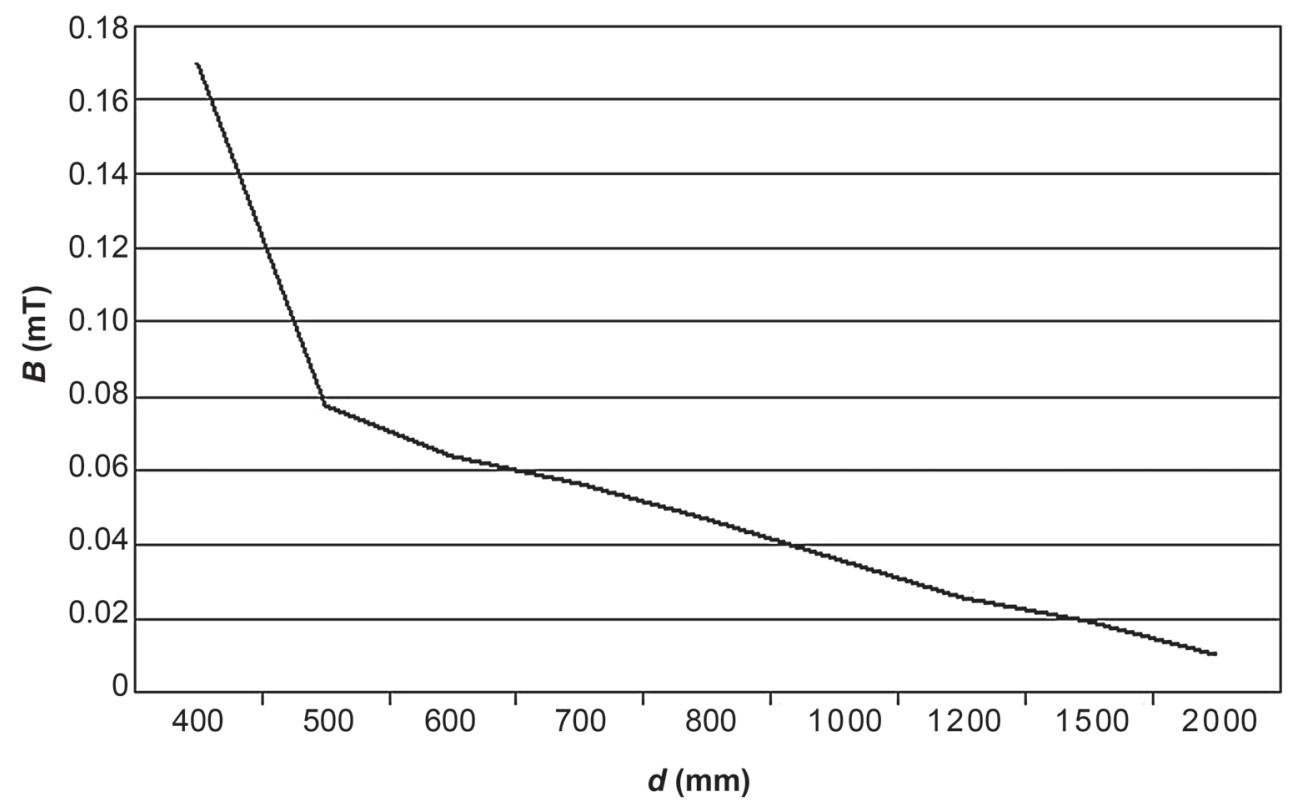

Figure 5. Dependence of magnetic flux density $B(\mathrm{mT})$ as a function of the distance from the busduct $d(\mathrm{~mm})$ (for greater distances from the busduct).

located under the ceiling which is the floor of the room above it (Figure 6). This is sometimes the case in industrial plants where offices are located above rooms with equipment supplying power to production bays or where power busducts for supplying welders, machines or electric (e.g., ultra high performance arc) furnaces are located on the walls adjacent to offices $[4,13,14]$.

\section{INDIRECT HAZARD CAUSED BY DEGRADED MECHANICAL STRUCTURES}

Heavy-current busducts are suspended under ceilings or assembled on special supporting structures [4, 13]. In both cases the fixing elements are ferroconcrete. The magnetic field generated by the busducts interacts with 
(a)

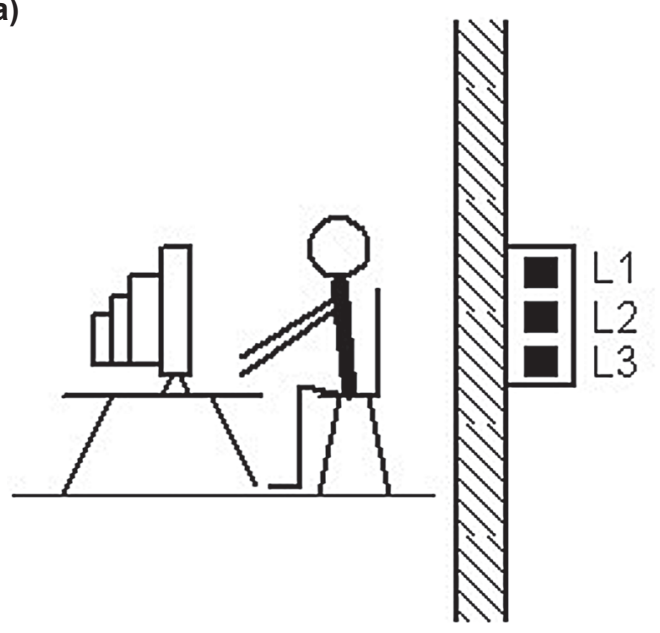

(b)

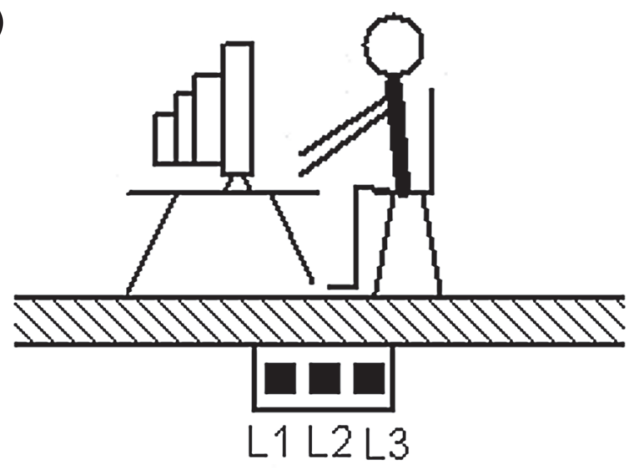

Figure 6. Examples of unsuitable arrangements of workstands near busducts: (a) interaction through a wall, (b) interaction through a floor. Notes. L1, L2, L3-phase conductors.

the ferromagnetic parts (i.e., the reinforcing rods) of the structures. So, eddy currents are generated in the steel elements, which as a result of heat generation, is conducive to power loss. Considerable local temperature shocks can lead to the structure breaking or a drastic decrease in its strength. In extreme cases, this can be hazardous for people working in the vicinity.

To perform a deeper analysis, electrodynamical calculations were done for a ferromagnetic frame located above a three-phase busduct (Figure 7). The geometry of the busduct is

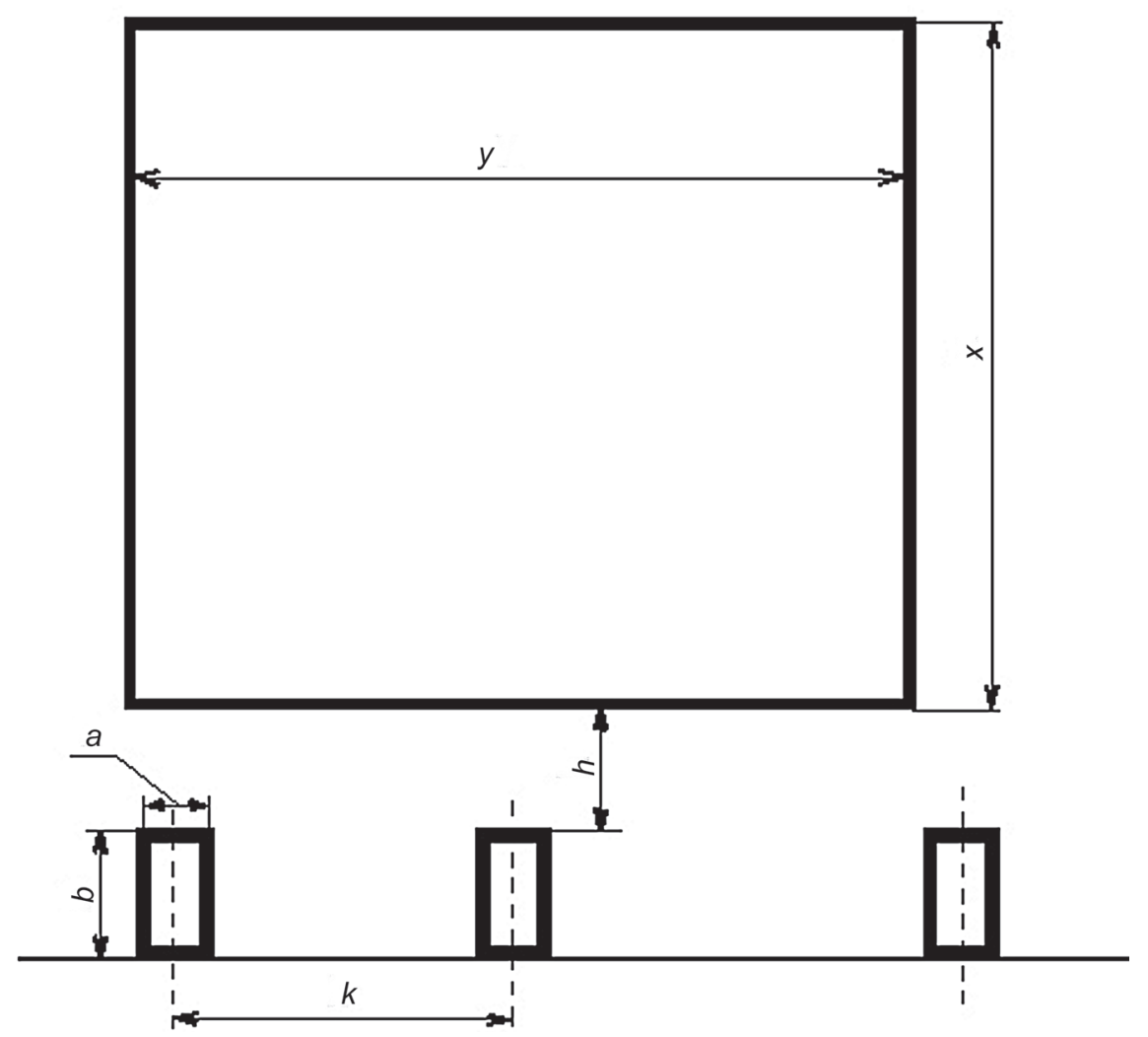

Figure 7. Arrangement of a ferromagnetic frame located above a busduct. Notes. $a, b$-dimensions of conductors, $k$-distance between axes of conductors, $h$-distance between busduct and frame. 


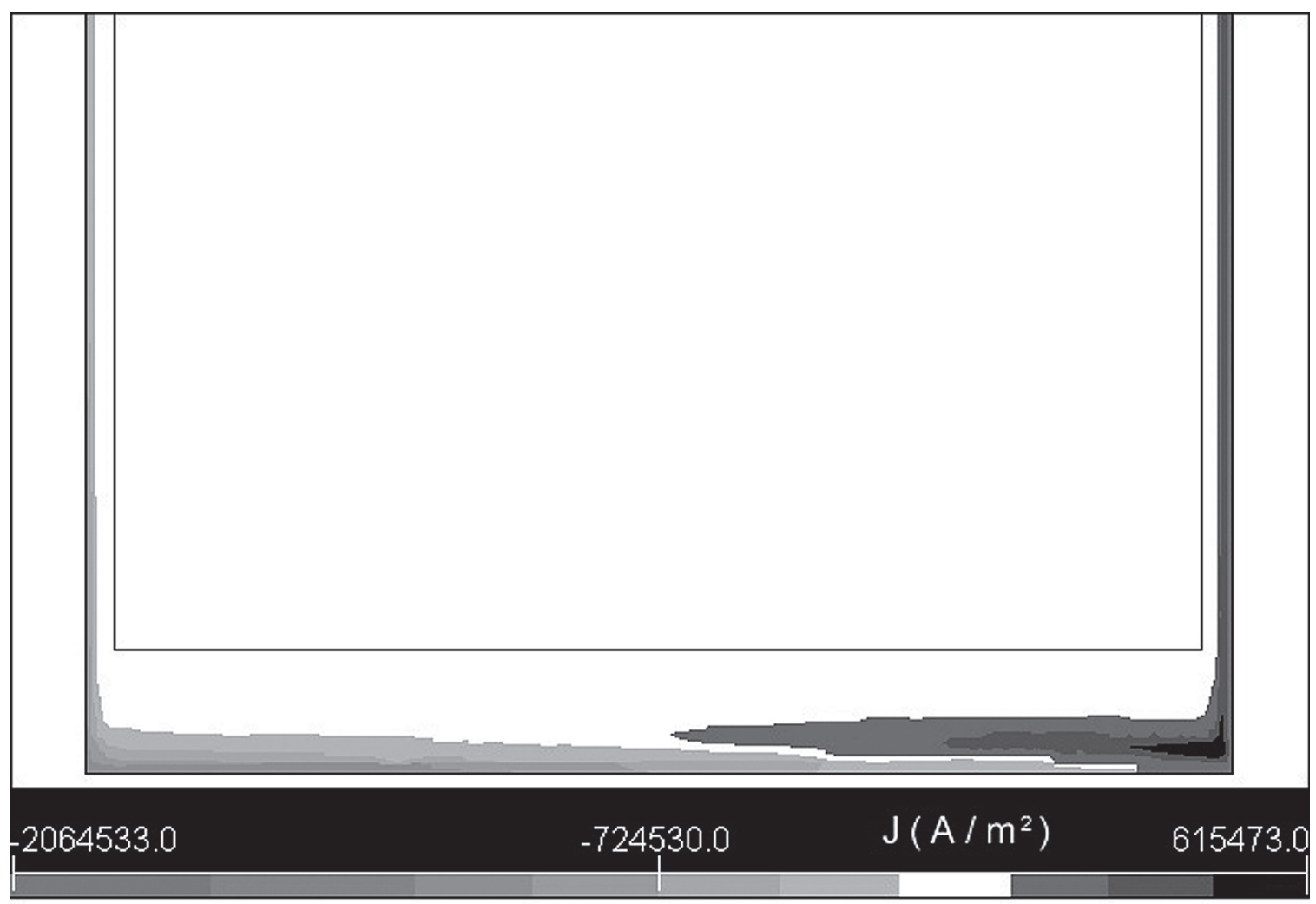

Figure 8. Distribution of current density $J\left(A / \mathrm{m}^{2}\right)$ induced in the bottom part of the frame of the system shown in Figure 7, at phase current of $I_{n}=4000 \mathrm{~A}$ (the bottom rod of the frame is magnified).

similar to the case in section 4 . The dimensions of the frame were $x=y=300 \mathrm{~mm}$. It was made of a steel wire with a cross-section of $8 \mathrm{~mm}^{2}$. The frame was suspended above the busduct at $h=50 \mathrm{~mm}$. The current of 4000 A flew through the phase conductors. The values of the density of the induced current $J\left(\mathrm{~A} / \mathrm{m}^{2}\right)$ and surface density of power loss in the frame $p_{\mathrm{S}}\left(\mathrm{W} / \mathrm{m}^{2}\right)$ were determined in the conductors and the frame (i.e., corresponding to definite discretized surface elements). The computation was done with specialized software designed for simulating electromagnetic fields (Opera 2D from Vector Fields, UK). Figures 8-9 show the results. To provide better representation of the local character of the observed phenomena the distribution of the density of the current induced in the region of the bottom rod of the frame (Figure 8) and the distribution of the density of the surface power loss near the bottom rod of the frame (Figure 9) are illustrated accordingly in geometric magnification.
The bottom parts of the figures with the results of calculations include scales showing numerical values corresponding to colours or shades of grey. A varying magnetic field induces eddy currents in the frame leading, according to Joule's law, to power loss and heat emission. The maximal value of the density of current (corresponding to elementary surfaces) induced in the ferromagnetic frame located above the busduct is $2 \cdot 10^{6} \mathrm{~A} / \mathrm{m}^{2}$. This is conducive to considerable power loss transformed into heat (manifesting itself by local growth of the temperature of the frame). This is confirmed by computations of the distribution of surface density of power loss (corresponding to discretized surface elements) that, in the considered case, exceeds $1.7 \cdot 10^{6} \mathrm{~W} / \mathrm{m}^{2}$. The analyses indicate that in the case of higher magnetic fields the temperature of ferromagnetic elements can considerably increase locally, which can lead to mechanical degradation. 


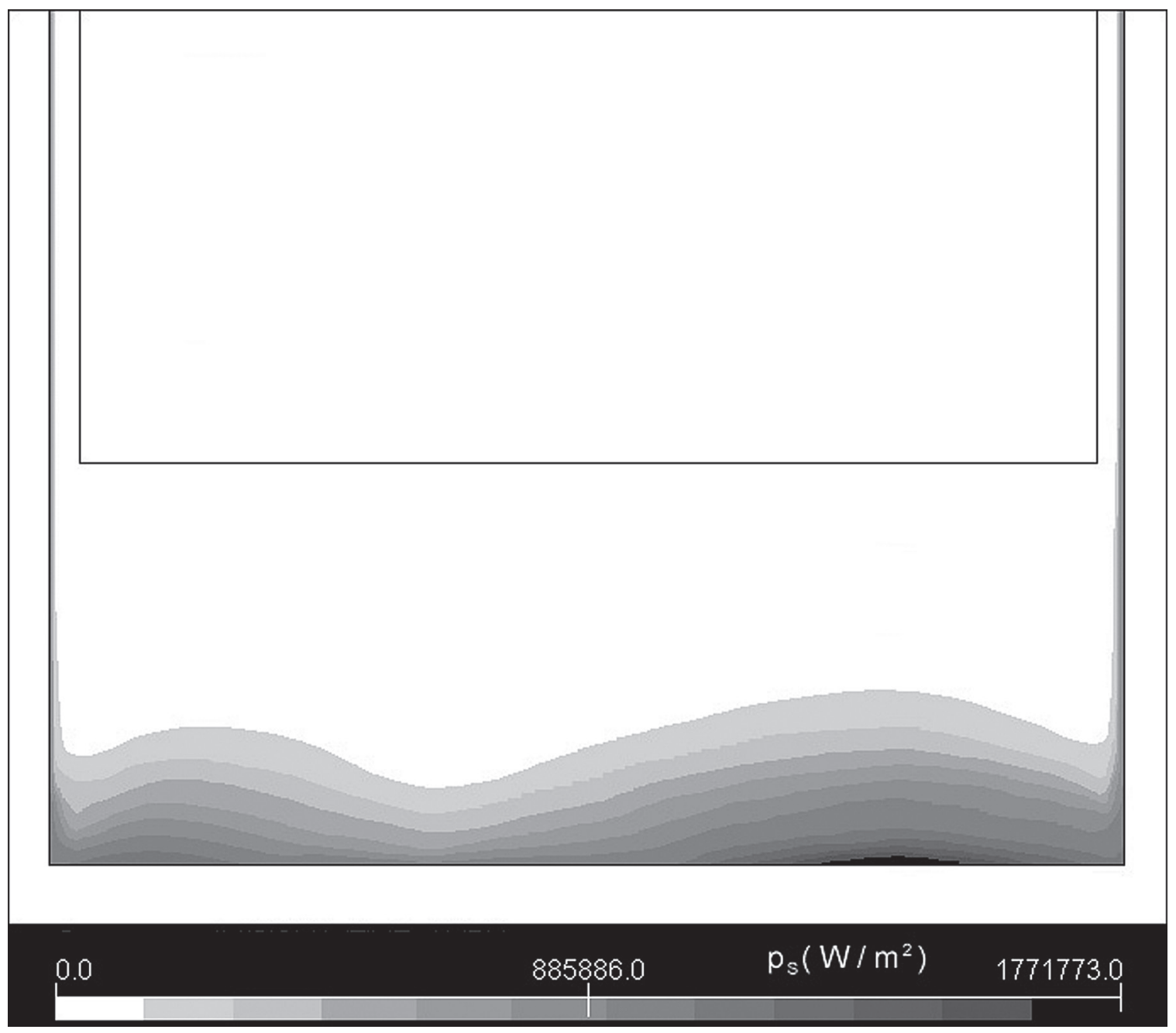

Figure 9. Distribution of surface density of power loss $p_{\mathrm{S}}\left(\mathrm{W} / \mathrm{m}^{2}\right)$ (corresponding to discretized surface elements) in the bottom part of the frame for the system in Figure 7, at phase current of $I_{\mathrm{n}}=4000 \mathrm{~A}$ (the bottom rod of the frame is magnified).

\section{ERGONOMIC ASPECTS OF THE INTERACTION OF SLOWLY-VARYING EMF WITH COMPUTER MONITORS}

Electromagnetic disturbances emitted by heavycurrent equipment (i.e., fields generated during its operation) can adversely affect other electric systems and devices. Disturbing signals reaching a sensitive device cumulate with useful signals. If the disturbing frequency approximates the range of the frequency of a sensitive device, the disturbance passes undamped through input filters. This happens both in analog and digital systems. As a result, the disturbed device can operate incorrectly or can even be damaged. Therefore, disturbing sources should be duly identified to eliminate or reduce their interaction. Incorrect operation of equipment can also negatively affect the ergonomic conditions of its operators. This is another reason why it is necessary to identify sources of electromagnetic sources.

CRT (cathode ray tube) computer monitors are highly sensitive to the interaction of magnetic field of $50 \mathrm{~Hz}$. The magnetic flux density field of several microteslas can be conducive to disturbances manifesting themselves as monitor image oscillation (jitter) $[15,16,17$, $18,19,20]$. The frequency of oscillation can equal to the difference between the frequencies of the interacting field and the refreshing of the image, and can be highly annoying. The worsened ergonomic working conditions can 
result in reduced efficiency or no work at all. Moreover, workers who do not understand electromagnetism might share the common belief that a magnetic field that causes an interaction with the monitor must be harmful for humans, even though the intensity of the field is significantly below the standard threshold determined for human body.

The calculations and EMF measurements made near heavy-current busducts, and the examinations and analyses carried out in several companies show that CRT computer monitors can operate incorrectly even over $2 \mathrm{~m}$ from busducts $[1,4,13,14,17,18,19]$. This was the situation, e.g., in the control room of a CHP (combined heat and power) plant and in production plants of the automotive industry, where busducts supplying a production bay were located under offices. The magnetic flux density in the working area was below the admissible level with respect to interaction with the human body, but equipment did not operate properly. Therefore, computer stands should not be located near heavy-current busducts (cf. Figure 6).

If computers monitors do not operate properly, the following can be done to avoid jitter $[15,16$, 17, 18, 19, 20]:

- moving the computer stand away from the source of EMF since the effect of the magnetic field decreases with an increase in the distance from the source of the field;

- replacing a CRT monitor with an LCD (liquid crystal display) one, which is not susceptible to interaction with a $50-\mathrm{Hz}$ field;

- using a magnetic screen either for the monitor or for the source of the field;

- decreasing the level of the magnetic field (e.g., by switching off devices that are not used or are idle).

\section{FINAL NOTES AND CONCLUSIONS}

This paper is based on theoretical analyses and tests on physical objects in laboratories and at workstands [1, 4, 13, 14, 17, 18, 19]. The results indicate that in the direct vicinity (i.e., usually below $1 \mathrm{~m}$ ) of heavy-current equipment like busducts, there is a significant magnetic field of of the order of milliteslas. This can be hazardous for people working in such an environment, both because of the direct interaction of the magnetic field with the human body and the secondary EMF effect on equipment.

Heavy-current busducts, as opposed to overhead lines, are sometimes located near workstands. For very small distances the effect of EMF can be important (there is an interaction in the proximate zone) and dangerous for the human body. Therefore, workstands should not be located near heavy-current busducts. On the other hand, technological conditions and the distribution of the magnetic field (the value of the magnetic flux density induced by the conductors would increase) make increasing the distance between phase conductors impossible.

Ferroconcrete structures used for supporting or suspending elements of power busducts can degrade due to strong electromagnetic interactions and large local temperature peaks. The difference in the thermal expansion of steel and concrete can cause concrete to crack. This can be a safety hazard for people in the vicinity of such a construction.

If CRT monitor screens are located near heavycurrent power equipment, computer operators can experience jitter, which can have an adverse psychological effect. The ergonomic conditions of the computer stand decrease then, too. Those factors prove that in the proximity of heavycurrent devices the magnetic field should be duly identified to avoid locating workstands in their immediate neighbourhood.

\section{REFERENCES}

1. Bednarek K. Normative and legal conditions pertaining to the effects of electromagnetic fields on human organism. Electrical Engineering. Computer applications in electrical engineering 2006 (Poznań University of Technology, Academic Journals, No. 52). Poznań, Poland: Poznań University of Technology; 2006. p. 91-101. 
2. Karpowicz J, Hietanen M, Gryz K. EU Directive, ICNIRP guidelines and Polish legislation on electromagnetic fields. International Journal of Occupational Safety and Ergonomics (JOSE). 2006;12(2): 125-36. Retrieved December 16, 2009, from: http://www.ciop.pl/17469

3. Garbarczyk Z, Kozłowski C, Nowicki M, Pachocki K. Zagrożenia elektromagnetyczne [Electromagnetic hazards] (Bezpieczeństwo $\mathrm{i}$ ochrona człowieka w środowisku pracy, 11) [Safety and the protection of human in the working environment, 11]. Warszawa, Poland: Central Institute for Labour Protection; 1998.

4. Bednarek K, Nawrowski R, Tomczewski A. Electromagnetic compatibility in the neighborhood of high-current lines. In: Krawczyk A, Wiak S, editors. Electromagnetic fields in electrical engineering (Studies in applied electromagnetics and mechanics, 22). Amsterdam, The Netherlands: IOS Press; 2002. p. 363-68.

5. Directive 2004/40/EC of the European Parliament and of the Council of 29 April 2004 on the minimum health and safety requirements regarding the exposure of workers to the risks arising from physical agents (electromagnetic fields) (18th individual Directive within the meaning of Article 16(1) of Directive 89/391/ EEC). OJ. 2004; L159:1-26. Retrieved December 16, 2009, from: http://eur-lex .europa.eu/LexUriServ/LexUriServ.do?uri= OJ:L:2004:159:0001:0026:EN:PDF

6. International Commission on Non-Ionizing Radiation Protection. Guidelines for limiting exposure to time-varying electric, magnetic and electromagnetic fields (up to $300 \mathrm{GHz}$ ). Health Phys. 1998;74(4):494-522. Retrieved December 16, 2009, from: http://www .icnirp.org/documents/emfgdl.pdf

7. Council Recommendation 1999/519/ EC of 12 July 1999 on the limitation of exposure of the general public to electromagnetic fields $(0 \mathrm{~Hz}$ to $300 \mathrm{GHz})$. OJ. 1999;L199:59-70.

8. Karpowicz J, Gryz K. Dyrektywa dotycząca ekspozycji zawodowej na pola elektromagnetyczne-2004/40/WE [Directive concerning occupational exposure to electromagnetic fields-2004/40/EC]. Bezpie- czeństwo Pracy. 2004;(11):20-3. In Polish, with an abstract in English. Retrieved December 16, 2009, from: http://www.ciop .pl/13560

9. World Health Organization, International Agency for Research on Cancer (IARC). Non-ionizing radiation, part 1: static and extremely low-frequency (ELF) electric and magnetic fields (IARC Monographs 80). Lyon, France: IARC Press; 2002. Retrieved December 16, 2009, from: http:// monographs.iarc.fr/ENG/Monographs/ vol80/volume80.pdf

10. ICNIRP Standing Committee on Epidemiology: Ahlbom A, Cardis E, Green A, Linet M, Savitz D, Swerdlow A. Review of the epidemiological literature on EMF and health. Environmental Health Perspective. 2001;109 Suppl 6:911-33. Retrieved December 16, 2009, from: http://www.icnirp .org/documents/EPIreview1.pdf

11. Regulation of the Minister of Labour and Social Policy of 29 November 2002 on maximum admissible concentrations and intensities for agents harmful to health in the working environment. Dz U. 2002;(217):item 1833. In Polish.

12. Regulation of the Minister of the Environment of 30 October 2003 on maximum admissible levels of electromagnetic fields in the environment and methods of checking adherence to these levels. Dz U. 2003;(192):item 1883. In Polish.

13. Bednarek K, Nawrowski R. Calculations and measurements of magnetic induction and power loss in surroundings of threephase conductors. In: Proceedings of $\mathrm{X}$ International Symposium on Theoretical Electrical Engineering. 1999. p. 429-34.

14. Bednarek K. Oddziaływania elektromagnetyczne torów wielkoprądowych [Electromagnetic influence of heavy-current busways]. Przeglad Elektrotechniczny. 2003;(12):897-9.

15. Sandström M. Electromagnetic fields in offices. International Journal of Occupational Safety and Ergonomics (JOSE). 2006;12(2):137-47. Retrieved December 16, 2009, from: http://www.ciop.pl/17470

16. Sandström M, Hansson Mild K, Lyskov E, Wilen J. Power frequency magnetic fields 
and computer monitor instability. Displays. 1998;19:85-90.

17. Bednarek K. Electromagnetic interaction and ergonomic aspect related to operation of computer monitors. In: Krawczyk A, Kubacki R, Wiak S, Lemos Antunes C, editors. Electromagnetic field, health and environment (Studies in applied electromagnetics and mechanics, 29). Amsterdam, The Netherlands: IOS Press; 2008. p. 32-7.

18. Bednarek K, Nawrowski R. Oddziaływanie na organizm człowieka pól magnetycznych i elektrycznych emitowanych przez monitory komputerowe [Interaction of computer monitor-emitted magnetic and electric fields with human organism]. In: Krawczyk A, editor. Bioelektromagnetyzm.
Warszawa, Poland: ZTUREK; 2002. p. 124-42.

19. Bednarek K. Problematyka wolnozmiennych pól magnetycznych i elektrycznych w monitorach komputerowych—zagadnienia emisyjności i odporności [The problems of slowly-varying magnetic and electric fields in computer monitors-the question of emissivity and immunity]. Elektryka. Zastosowanie komputerów w elektrotechnice 2005 (Poznań University of Technology, Academic Journals, No. 50). Poznań, Poland: Poznań University of Technology; 2006. p. 129-37.

20. Bugajska J, editor. Komputerowe stanowisko pracy-aspekty zdrowotne i ergonomiczne [Computer workstation. Health and ergonomics aspects]. Warszawa, Poland: Central Institute for Labour Protection; 1999. 